\title{
A Helminth Protease Inhibitor Modulates the Lipopolysaccharide-Induced Proinflammatory Phenotype of Microglia in vitro
}

\author{
Peter Behrendt ${ }^{a} \quad$ Philipp Arnold ${ }^{b} \quad$ Max Brueck ${ }^{b} \quad$ Uta Rickert $^{b} \quad$ Richard Lucius $^{c}$ \\ Susanne Hartmann ${ }^{d}$ Christian Klotz $^{\mathrm{e}}$ Ralph Lucius ${ }^{\mathrm{b}}$ \\ Departments of ${ }^{\mathrm{a}}$ Trauma Surgery and ${ }^{\mathrm{b}}$ Anatomy, University of Kiel, Kiel, and Departments of ${ }^{\mathrm{c}}$ Molecular \\ Parasitology and ${ }^{\mathrm{d}}$ Immunology, Humboldt University Berlin, and ${ }^{\mathrm{e}}$ Robert Koch Institute, Berlin, Germany
}

\section{Key Words}

Microglia · Neuroinflammation · Immunomodulation ·

Acanthocheilonema viteae - Cysteine protease inhibitor .

Interleukin-10 - Parasite

\section{Abstract \\ Objective: The aim of this study was to examine whether the natural protease inhibitor Av-cystatin (rAv17) of the parasit- ic nematode Acanthocheilonema viteae exerts anti-inflam- matory effects in an in vitro model of lipopolysaccharide (LPS)-activated microglia. Methods: Primary microglia were harvested from the brains of 2-day-old Wistar rats and cul- tured with or without rAv17 ( $250 \mathrm{nM})$. After 6 and $24 \mathrm{~h}$ the release of nitric oxide (Griess reagent) and TNF- $a$ (ELISA) was measured in the supernatant. Real-time PCR was performed after 2, 6 and $24 \mathrm{~h}$ of culture to measure the mRNA expres- sion of IL-1 $\beta$, IL-6, TNF-a, COX-2, iNOS and IL-10. To address the involved signaling pathways, nuclear NF-кB transloca- tion was visualized by immunocytochemistry. Morphologi- cal changes of microglia were analyzed by Coomassie blue staining. Differences between groups were calculated using one-way ANOVA with Bonferroni's post hoc test. Results: Morphological analysis indicated that LPS-induced microg-}

\section{KARGER}

C) 2016 S. Karger AG, Basel

$1021-7401 / 16 / 0232-0109 \$ 39.50 / 0$

E-Mail karger@karger.com

www.karger.com/nim lial transformation towards an amoeboid morphology is inhibited by rAv17. Av-cystatin caused a time-dependent downregulation of proinflammatory cytokines, iNOS and COX-2 mRNA expression, respectively. This was paralleled by an upregulated expression of IL-10 in resting as well as in LPS-stimulated microglia. Av-cystatin reduced the release of $\mathrm{NO}$ and TNF- $\mathrm{a}$ in the culture supernatant. Immunocytochemical staining demonstrated an attenuated translocation of NF-KB by Av-cystatin in response to LPS. In addition, Western blot analysis revealed a rAv17-dependent reduction of the LPS-induced ERK1/2-pathway activation. Conclusion: The parasite-derived secretion product Av-cystatin inhibits proinflammatory mechanisms of LPS-induced microglia with IL-10, a potential key mediator.

@ 2016 S. Karger AG, Basel

\section{Introduction}

Several investigators focus on the pathophysiology of neurodegenerative diseases (ND). In this context, a dysregulated response of the neuroimmune system - termed neuroinflammation - is a main contributor to the chronic progression of ND. Neuroinflammation is mainly ex- 
erted by activated microglia faced with protracted activating stimuli. Subsequently, such activated microglia acquire maladaptive functions and a proinflammatory phenotype. This makes microglial activation and adaption an interesting target in the study of potential immunomodulators.

However, the process of microglia activation seems to be more complex. Recent studies have investigated the plasticity of microglial cells and detailed gene expression analyses revealed that monomorphic-activated microglia might accomplish entire distinct functions. Like macrophages, microglial cells seem to be functionally polarized into different phenotypes, meaning that different activation states are known $[1,2]$.

Classical activation characterizes a phenotype that seems to dominate under neurodegenerative conditions. This phenotype is characterized by the production of proinflammatory cytokines (e.g. IL-1 $\beta$, IL-6, TNF- $\alpha$ ), nitric oxide (NO) and other reactive oxygen species [3]. Accordingly, enzymes such as iNOS (inducible NO-synthase) and COX-2 (cyclooxygenase 2) have also been associated with ND [3-6]. Such activated microglial cells promote neurodegeneration in experimental models in vitro and in vivo [7-9].

The second state is alternative activation, by which microglia take on an anti-inflammatory phenotype. Different markers have been described to characterize this phenotype. Another way to classify the function and phenotype of cells is based on the cytokines that induce them. According to this concept, immunomodulatory agents could be separated into those leading to a proinflammatory or an anti-inflammatory phenotype [1]. However, there is no gold standard set of markers that finally discriminates between these phenotypes.

Parasitic worms have evolved highly efficient mediators to protect themselves and the host tissues from this immune-mediated damage [10]. Here we use a member of the filarial cystatin family, recombinant Av-cystatin ( $\mathrm{rAv17}$ ), a 17-kDa protein of the parasitic nematode Acanthocheilonema viteae (Av). Cystatins belong to a family of cysteine protease inhibitors and represent important regulators of highly efficient proteolytic processes, such as the processing of protein precursors or antigen processing [11]. rAv17 is secreted, which suggests that it might have important functions in the host-parasite interplay. Cystatins produced by Av are protective in allergic airway pathology and colitis [12]. It was shown to affect monocytes and macrophages, which subsequently achieved a regulatory type-II-activated phenotype with anti-inflammatory properties $[13,14]$. One of the key cytokines inducing an anti-inflammatory phenotype is IL-10. IL-10 has extensive immune-regulatory properties in controlling and reducing an excessive immune response during infection or autoimmunity. This is mainly due to the suppressed production of proinflammatory cytokines in macrophages. In the context of cellular phenotypes, $\mathrm{T}$ helper (Th) cells are known to be functionally polarized into different T-cell phenotypes and IL-10 is an important regulator towards Th2-cells. Here, using a cell culture model of primary rat microglia, we demonstrate that the application of rAv17 modulates the classical activation state of lipopolysaccharide (LPS)-stimulated microglia in vitro, thereby reducing the expression of proinflammatory cytokines and elevating the expression of IL-10.

\section{Materials and Methods}

\section{Microglia Cell Culture}

Wistar rats were used for all experiments and were bred and kept under constant conditions (12/12 h light/dark cycle) in the animal house of the University of Kiel. Primary cultures were prepared from rostral mesencephali and cerebral hemispheres of 2 -day-old rats. The meninges, hippocampi and choroid plexus were removed from the brains, and the cortices and mesencephali were minced and mechanically dissociated by trituration using fire-polished Pasteur pipettes, followed by enzymatic digestion with trypsin (from bovine pancreas, type III; Invitrogen) and DNAse I (Roche). Suspended mixed brain cells were plated in a culture flask (diameter $100 \mathrm{~mm}$; Sarstedt) in $10 \mathrm{ml}$ of growth medium (DMEM; Invitrogen) supplemented with $10 \%$ fetal bovine serum (Invitrogen), L-glutamine (Sigma), 1\% penicillin (10,000 U/ $\mathrm{ml}$; PAA) and streptomycin $(10 \mathrm{mg} / \mathrm{ml}$; PAA). All cells were cultured in a humidified atmosphere enriched with $5 \% \mathrm{CO}_{2}$. Freefloating microglial cells were collected from the medium of primary cell cultures from neonatal rat cerebral cortices after 10 days, as described previously [15]. Prior to replanting the microglial cells for the different experiments, the cell number and viability was estimated by trypan-blue exclusion. Viable cells were seeded onto 12 -well culture plates [100,000 cells/well for Coomassie and immunocytochemical staining and 1,000,000 cells/well for quantitative real-time PCR (q-PCR), NO measurement, ELISA and Western blot] and grown for $24 \mathrm{~h}$ at $37^{\circ} \mathrm{C}$ in a humidified atmosphere enriched with $5 \% \mathrm{CO}_{2}$. For the observation of morphological changes in cell shape, the cells were fixed with $2 \%$ glutaraldehyde in phosphate-buffered saline (PBS) after $24 \mathrm{~h}$ of stimulation and stained with Coomassie blue dye (Bio-Rad). Cell analysis was performed from three independent experiments using an Axiophot microscope (Zeiss, Wetzlar, Germany) with a $40 \times$ objective and $10 \times$ eye piece. The mean value of pseudopodia from each section was calculated based on a total of 30 cells for each experimental subgroup. The quantitative size objectification was performed for the same cells using the computer software ImageJ.

\section{Treatment of Cells}

Recombinant and LPS-free rAv17 was produced according to Schnoeller et al. [12]. For the induction of microglial activation, 
LPS (10 ng/ml, from Salmonella typhimurium; Sigma), a bacterial endotoxin and generally accepted inducer of proinflammatory properties $[16,17]$, was added to the positive control groups. The experimental groups were incubated with the recombinant immunomodulatory protein rAv17 (low dose, $250 \mathrm{nM}$; high dose, 500 $\mathrm{nM}$ ), dissolved in PBS (Gibco), or with LPS and rAv17. The control groups remained untreated. As the end points of stimulation we chose $24 \mathrm{~h}$ for morphological analyses, 6 and $24 \mathrm{~h}$ for nitrite measurements, 2, 6 and $24 \mathrm{~h}$ for q-PCR, 6 and $24 \mathrm{~h}$ for TNF- $\alpha$-ELISA, $15 \mathrm{~min}$ for Western blot analyses and $60 \mathrm{~min}$ for NF- $\kappa \mathrm{B}$ staining. For stimulating experiments the experimental groups were incubated with LPS and rAv17 simultaneously, except from Western blot experiments where microglia were preincubated with rAv17 30 min before the LPS was added.

\section{Measurement of Nitrite Production}

The nitrite concentration in the culture supernatant was used as a measure of NO production. After 6 and $24 \mathrm{~h}$ of incubation, the generation of NO in the cell culture supernatants was determined by measuring nitrite accumulation in the medium using Griess reagent $(0.5 \%$ sulfanilamide and $0.05 \% \mathrm{~N}$-(1-naphthyl)ethylenediamine dihydrochloride in $0.25 \% \mathrm{H}_{3} \mathrm{PO}_{4}$; Sigma). One hundred microliters of culture supernatant and $100 \mu \mathrm{l}$ of Griess reagent were mixed and incubated for $5 \mathrm{~min}$. The absorption was estimated in an automated plate reader (SLT reader 340 ATTC) at $540 \mathrm{~nm}$. For both concentrations of rAv17 the results were obtained from three independent experiments of identically treated cells.

\section{Quantitative Real-Time PCR}

After 2, 6 and $24 \mathrm{~h}$ of incubation the cell supernatant was discarded and the microglia were washed three times with $\mathrm{PBS}\left(4^{\circ} \mathrm{C}\right)$. RNA was isolated with the QIAzol reagent and contaminating DNA was digested by DNase (Promega, Mannheim, Germany). In the next step the RNA was transcribed in cDNA using random hexamer primer (Fermentas) and reverse transcriptase (RevertAid $^{\text {TM }} \mathrm{H}$ Minus M-muLV; Fermentas). Ten nanograms of cDNA were used for q-PCR amplification. q-PCR was performed in two replicates of each sample using TaqMan ${ }^{\circledR}$ primer probes (assayson-demand; Applied Biosystems) on an ABI Prism 7000 thermocycler using assays-on-demand and chemistries as recommended by the manufacturer (all Applied Biosystems). The q-PCR signal of the target transcript in the treatment groups was related to that of the control by relative quantification. The $2^{-\Delta \Delta C_{\mathrm{T}}}$ method was used to analyze the relative changes in gene expression. The housekeeping gene 18s rRNA was used as an internal control to normalize the q-PCR for the amount of RNA added to the reverse transcription reactions. Data are expressed as the percent change of gene expression relative to LPS-stimulated controls (100\%). TaqMan assays had the following identification numbers: 18s: Hs 99999901, iNOS: Rn 00561646, TNFa: Rn 99999017, IL-6: Rn 00561420, IL-1 $\beta$ : Rn 00580432, IL-10: Rn00563409, COX-2: Rn00568225.

\section{Enzyme Immune Assay of TNF- $\alpha$}

TNF- $\alpha$ protein in microglia culture supernatants was measured by solid-phase sandwich enzyme-linked immunosorbent assay (ELISA), using a monoclonal capture antibody specific for TNF- $a$ protein (all antibodies from BD Bioscience, Franklin Lakes, N.J., USA). TNF- $\alpha$ ELISA was performed using the BD OptEIA TNF-
ELISA-Kit (all from BD Bioscience). After 6 and $24 \mathrm{~h}$ of incubation, collected culture medium was harvested and treated according to the instructions of the manufacturer. The wells of a 96-microtiter plate were coated with the TNF- $\alpha$ capture antibody overnight at $4^{\circ} \mathrm{C}$. Wells were blocked with assay diluent and incubated with $100 \mathrm{ml}$ of the culture supernatant at room temperature for $2 \mathrm{~h}$. Antibody binding was detected via biotin-conjugated detection antibody and the manufacturer's substrate reagent set. The concentration of TNF- $\alpha$ was calculated according to the equation obtained from the standard curve plot using the TNF- $\alpha$ standard solution provided with the ELISA kit.

\section{Immunocytochemical NF- $\kappa B$ Staining}

To assess the activity of the NF- $\mathrm{kB}$ pathway, we visualized the translocation of the p65 subunit into the nucleus. Isolated microglia were cultured onto coverslips for $24 \mathrm{~h}$ and fixed with Zamboni's reagent (4\% paraformaldehyde and $0.2 \%$ picric acid, dissolved in PBS) for $1 \mathrm{~h}$ at room temperature. Afterwards, the cells were stained with antibodies against NF-kB p65 (Santa Cruz Biotechnology) for $60 \mathrm{~min}$ at room temperature and in a second step with fluorescent anti-rabbit antibodies (Invitrogen) for 45 min at room temperature. The immunoreaction was visualized by fluorescence microscopy (Zeiss Axiovert, Carl Zeiss Microscopy). The quantitative objectification from each section was calculated based on a total of 10 cells for each experimental subgroup. The objectification was done via densitometric analysis using ImageJ computer software and the results for cells treated with rAv17 were compared to those stimulated solely with LPS (100\%).

\section{Western Blot Analysis}

For Western blot analysis microglial cells were pretreated with rAv17 (250 nM) for 30 min before stimulation with $10 \mathrm{ng} /$ $\mathrm{ml}$ of LPS. After $15 \mathrm{~min}$ of incubation the cell supernatant was discarded and the microglia were washed twice with $\mathrm{PBS}\left(4^{\circ} \mathrm{C}\right)$, harvested in PBS by scraping, and centrifuged. Cellular protein was isolated from the cells using $100 \mu \mathrm{l}$ of lysis buffer $(199 \mathrm{mM}$ $\mathrm{NaCl}, 50$ mM TRIS, 5 mM EDTA, 1\% Triton X-100, 2 mM sodium vanadate, $2.5 \mathrm{~mm}$ sodium pyrophosphate, $1 \mathrm{~mm} \beta$-glycerol phosphate, $1 \mathrm{~mm}$ phenylmethylsulfonyl fluoride). Protein aliquots (5 $\mu \mathrm{g}$ ) were sorted by $12.5 \%$ SDS-PAGE and Western blotted with phospho-specific antibodies against phosphorylated ERK (pERK1/2; Cell Signaling Technology, Danvers, Mass., USA) overnight at $4^{\circ} \mathrm{C}$ according to the manufacturer's protocol. Antibody binding was detected via enhanced chemiluminescence (Amersham Pharmacia Biotech, Essex, UK). The quantitative objectification was done via densitometric analysis using computer software PC-BAS 2.0.

\section{Statistical Analysis}

All experiments were performed at least three times and values represent the mean \pm standard error of the mean (SEM). Statistical analysis of the data was accomplished using a one-way ANOVA indicating significant differences, and comparisons among the various experimental groups was made using Bonferroni's post hoc test. Student's t test was used when two groups were considered. Differences were considered significant with $\mathrm{p} \leq 0.05$. Quantitative data are presented as the mean \pm SEM and confidence intervals (CI; lower limit, upper limit); $\mathrm{n}$ represents the number of independent experiments. 
Fig. 1. a-e LPS-induced transformation of ramified microglia is blocked by rAv17. Representative photomicrographs of in vitro-cultivated microglia. a Resting microglia cells (control). b LPS (10 ng/ml)-stimulated amoeboid microglia (positive control). c The addition of rAv17 (250 nM) did not alter the morphology of resting microglia. d rAv17 (250 nM) inhibited the LPS (10 ng/ml)-induced amoeboid microglia transformation. Scale bar $=20 \mu \mathrm{m}$. e This interpretation was confirmed by the quantification of the cell area $(\mathrm{ca} ; \mu \mathrm{m})$ and counting the number of pseudopodia (p). The data were assessed from 30 cells per experimental subgroup of three independent experiments. Letters ( $a, b, c, A, B)$ indicate clusters of experimental groups which are significantly different from each other $(\mathrm{p}<0.05)$. All data are the mean \pm SEM ( $95 \%$ CI values are given in the text). Cells were cultivated upon cover glasses and stimulated with the indicated reagents for $24 \mathrm{~h}$. After fixation with $2.5 \%$ glutaraldehyde cells were stained with Coomassie blue dye.

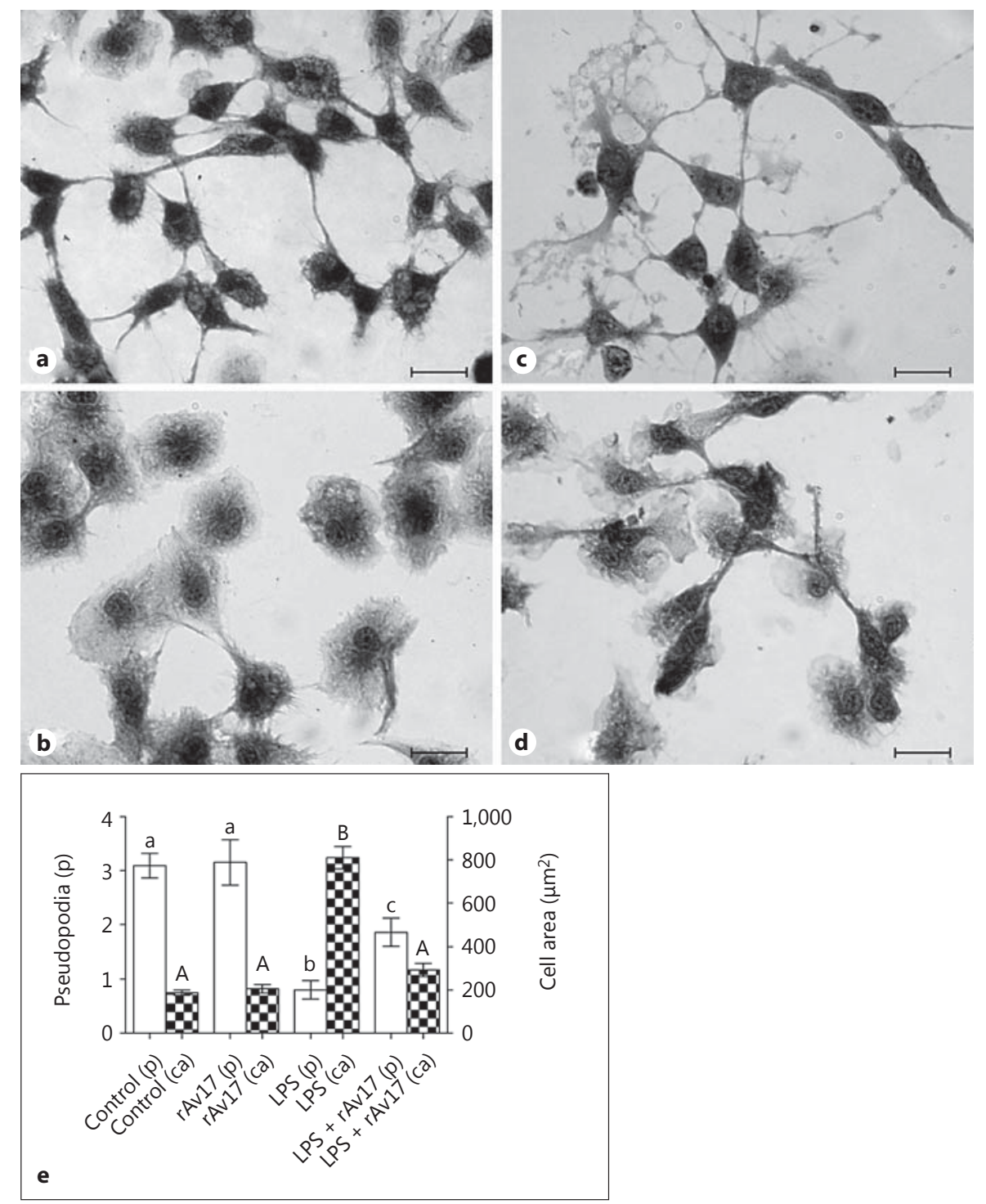

\section{Results}

Morphological Alterations of Microglia Cells by rAv17

To examine whether rAv17 alters the morphology of microglia in vitro, we exposed cells to the protein in the absence and presence of LPS for $24 \mathrm{~h}$ and measured the number of pseudopodia and the cell size (cell area). Untreated cells (fig. 1a) developed the typical ramified morphology of resting microglia [18] with a small cell size (187 $\pm 11.4 \mu^{2}$, 95\% CI 163-211) and numerous pseudopodia (3.1 \pm 0.23 ; 95\% CI 2.62-3.57). In comparison, LPS-stimulated cells (fig. 1b) presented the characteristic amoeboid phenotype of activated microglia with significantly larger soma $\left(811 \pm 51.7 \mu \mathrm{m}^{2} ; 95 \%\right.$ CI $\left.702-919 ; \mathrm{p}<0.001\right)$ and a reduced number of pseudopodia $(0.8 \pm 0.17 ; 95 \%$ CI $0.44-$ $1.16 ; \mathrm{p}<0.001)$. The addition of $\mathrm{rAv} 17$ alone did not result in an LPS-like phenotype transformation (fig. 1c), but was very similar to resting microglia. There was neither a significant reduction of pseudopodia $(3.15 \pm 0.42 ; 95 \%$ CI 2.24-4.07; p > 0.05) nor an increased cell size (205 \pm 19.7 $\mu \mathrm{m}^{2}$; 95\% CI 162-248; $\left.\mathrm{p}>0.05\right)$. The shape of the microglia simultaneously exposed to LPS and rAv17 resembled a mixed phenotype (fig. 1d); nevertheless, they presented significantly more pseudopodia $(1.87 \pm 0.26$; $95 \%$ CI $1.32-$ 2.42; $\mathrm{p}<0.05)$ and a smaller soma $\left(293 \pm 30.4 \mu \mathrm{m}^{2}\right.$; $95 \%$ CI 227-358; $\mathrm{p}<0.001)$ compared to LPS-treated cells. This indicates that microglial transformation towards an amoeboid morphology is partly inhibited by rAv17. 


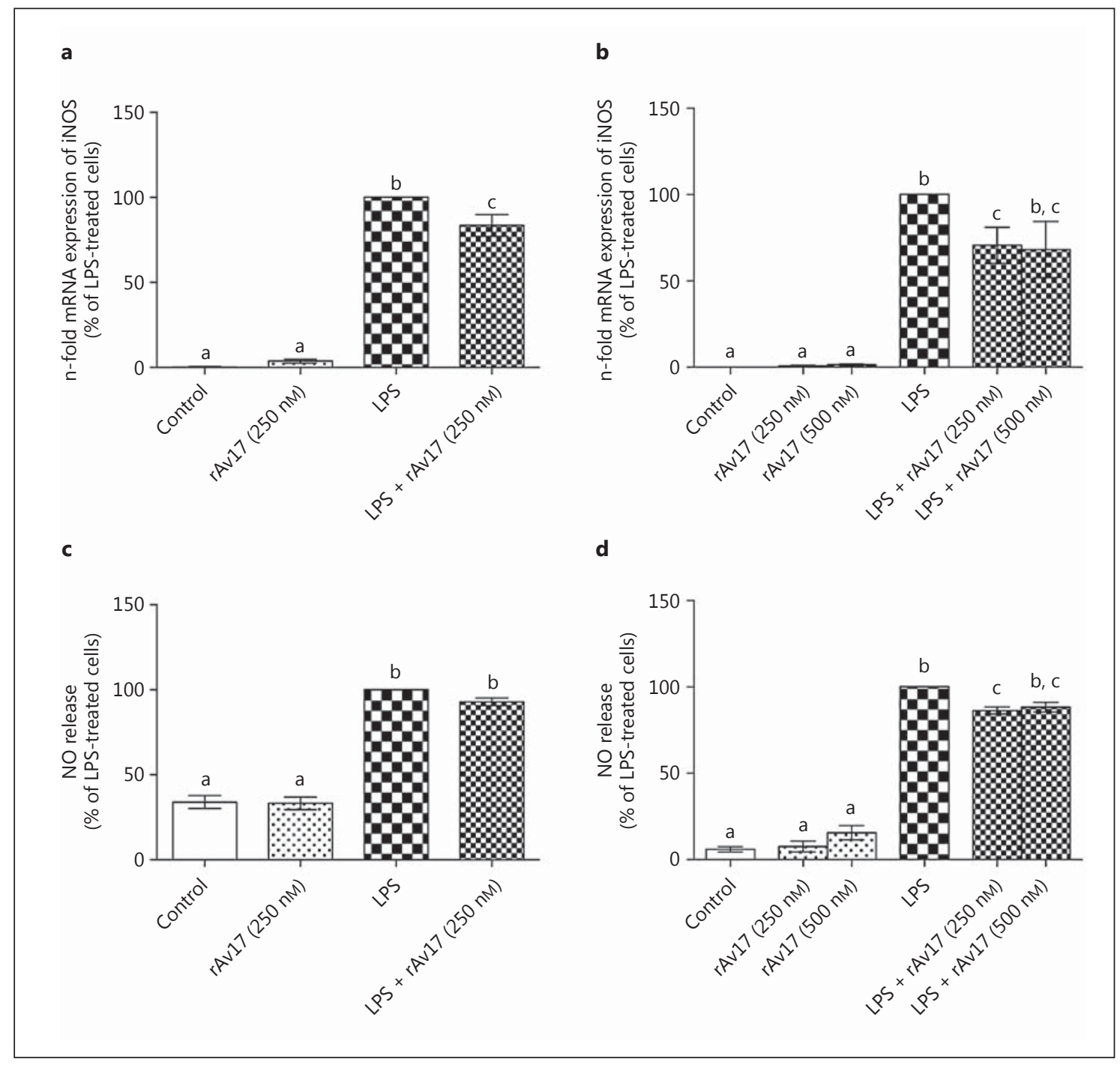

Fig. 2. The immunomodulator rAv17 reduces the expression of iNOS mRNA $(\mathbf{a}, \mathbf{b})$ and the NO synthesis $(\mathbf{c}, \mathbf{d})$ in cultivated microglia. Cells were stimulated for $6(\mathbf{a}, \mathbf{c})$ and $24 \mathrm{~h}(\mathbf{b}, \mathbf{d})$ with rAv17 (250 $\mathrm{nM}$ at $6 \mathrm{~h}, 250$ and $500 \mathrm{nM}$ at $24 \mathrm{~h})$, LPS (10 ng/ml) and simultaneously with rAv17 + LPS, respectively. mRNA expression was analyzed using TaqMan q-PCR and results for cells treated with rAv17 were compared to those stimulated solely with LPS. 18s
RNA (a housekeeping gene) was used as the internal control. The data were assessed from at least 3 independent experiments, each run in duplicate. Letters $(a, b, c)$ indicate clusters of experimental groups which are significantly different from each other $(p<0.05$; detailed $\mathrm{p}$ values are given in the text). All data are the mean \pm SEM (95\% CI values are given in the text).
rAv17 Reduces LPS-Induced Expression of iNOS $m R N A$ and NO Synthesis in Microglia

LPS induced the expression of iNOS and mediated the production of large amounts of NO in microglia $[19,20]$. To test whether $\mathrm{rAv} 17$ reduces the amount of $\mathrm{NO}$ radicals, we exposed microglia to the protein in the absence or presence of LPS. Sole rAv17 (250 nM) did not alter the levels of iNOS mRNA expression (6 h: $3.80 \pm 1.1 \%$; $95 \%$ CI $0.22-7.23 ; 24$ h: $0.67 \pm 0.33 \%$; $95 \%$ CI $-0.77-2.11)$ and
NO release (6 h: $33.26 \pm 3.7 \%$; $95 \%$ CI $21.57-44.59 ; 24$ h: $7.58 \pm 3.2 \%$; $95 \%$ CI -2.44 to 17.61$)$ at both time points. In contrast, LPS significantly increased both parameters at 6 and $24 \mathrm{~h}$ (each 100\%). Simultaneous exposure to LPS and $\mathrm{rAv17}(250 \mathrm{nM})$ significantly reduced the level of LPS-induced iNOS mRNA at $6 \mathrm{~h}(83.51 \pm 6.46 \%$; $95 \% \mathrm{CI}$ 62.94-104.1; $\mathrm{p}<0.05)$ and $24 \mathrm{~h}(70.67 \pm 10.35 \%$; $95 \% \mathrm{CI}$ 26.14-115.20; $\mathrm{p}<0.05$; fig. 2a, b). Additionally, this was accompanied by a reduction of $\mathrm{NO}$ at $6 \mathrm{~h}$ (trend: $92.88 \pm$ 


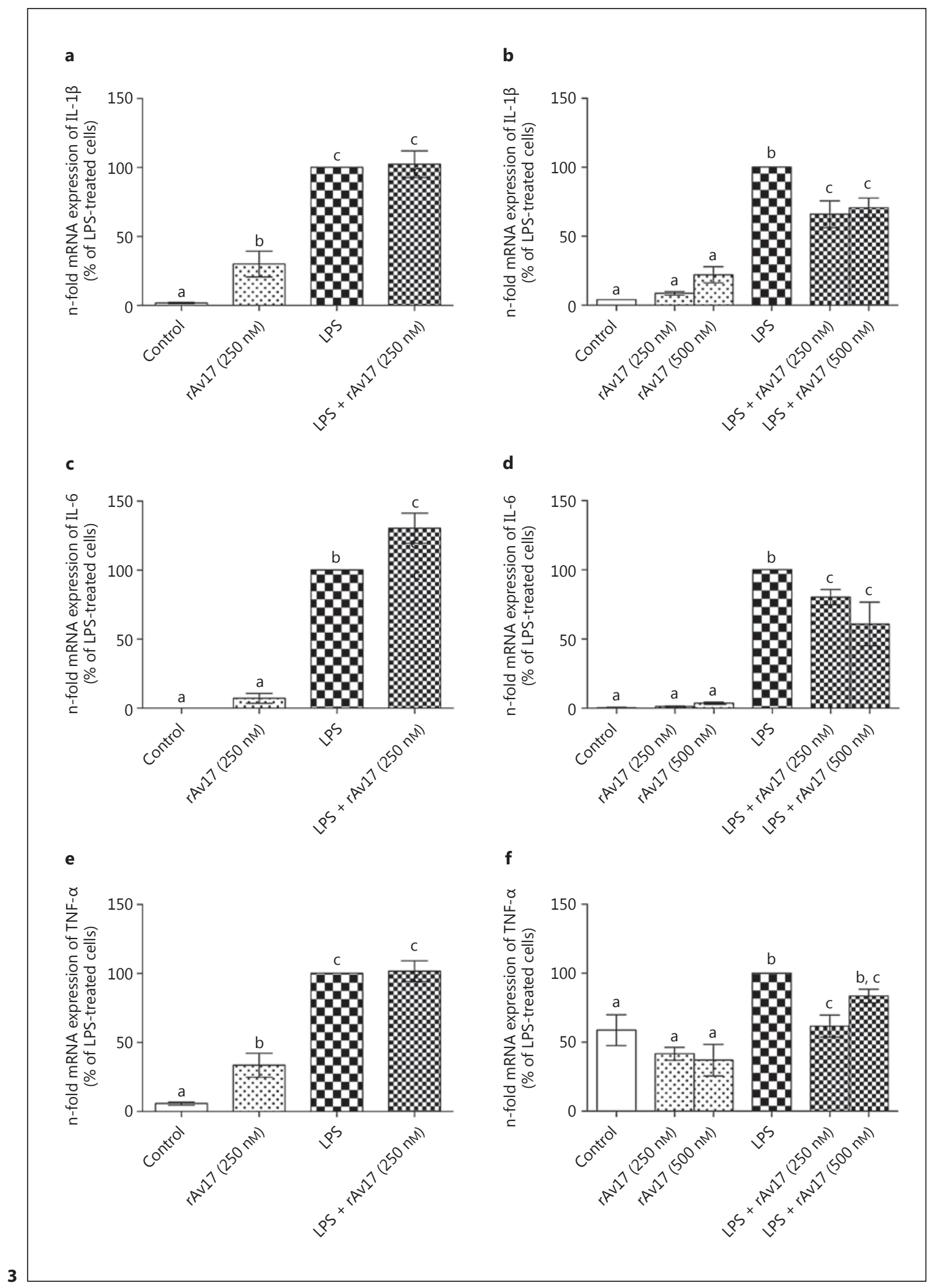

(For legend see next page.) 
2.25\%; 95\% CI 85.72-100.0; not significant) and significantly at $24 \mathrm{~h}(86.34 \pm 2.01 \%$; $95 \%$ CI $79.73-92.95 ; \mathrm{p}<$ 0.01 ; fig. $2 \mathrm{c}, \mathrm{d}$ ). Thus, the reduced production of NO radicals seems to be mediated in part by inhibited iNOS expression in LPS-stimulated microglia. Experiments with a higher molecular dosage of rAv17 (500 nM) showed a comparable effect with respect to LPS without reaching significance [LPS + rAv17 (500 nM): iNOS, $24 \mathrm{~h}: 68.2 \pm$ $16.3 \%$; 95\% CI 16.3-120.0; p > 0.05; NO, 24 h: $88.3 \pm$ $2.71 \%$; 95\% CI 76.68-99.98; $\mathrm{p}>0.05$ ].

\section{rAv17 Inhibits Proinflammatory Cytokine}

$m R N A$ Expression and TNF- $\alpha$ Release by

Microglia in a Time-Dependent Manner

LPS-activated microglia produce an array of neurotoxic proinflammatory cytokines like IL-1 $\beta$, IL- 6 and TNF- $\alpha$ [21]. To study the capacity of rAv17 to modulate the production of these proinflammatory cytokines, we exposed microglia to the protein in the absence or presence of LPS and analyzed the mRNA expression of IL-1 $\beta$, IL- 6 and TNF- $\alpha$ by q-PCR. rAv17 (250 nM) alone significantly increased the level of IL- $1 \beta(30.0 \pm 9.37 \%$; $95 \%$ CI 5.9-54.1) and TNF- $\alpha$ mRNA $(33.5 \pm 8.65 \%$; $95 \%$ CI 5.99 $61.01)$ at $6 \mathrm{~h}$ (both $\mathrm{p}<0.05)$ but not at $24 \mathrm{~h}(\mathrm{IL}-1 \beta: 8.67 \pm$ 1.20\%; 95\% CI 3.49-13.84; TNF- $\alpha$ : $41.67 \pm 4.7 \%$; 95\% CI 21.43-61.9; fig. 3a, b, e, f), whereas it did not alter the levels of IL-6 mRNA ( 6 h: $7.0 \pm 3.51 \%$; 95\% CI -8.11-22.1; 24 h: $1.33 \pm 0.33 \%$; $95 \%$ CI -0.10 to 2.77 ; fig. $3 b-d)$. In contrast, LPS induced a substantial rise of all measured cytokine mRNAs (100\%). Simultaneous exposure of microglia to rAv17 and LPS revealed a time-dependent effect of rAv17 on LPS-induced cytokine expression. After $6 \mathrm{~h}$ the effect of rAv17 (250 nM) modulation was heterogeneous. It significantly $(\mathrm{p}<0.05)$ increased the level of IL-6 mRNA (130.4 $\pm 10.8 \%$; 95\% CI 83.64-177.2) while having no effects on the expression levels of IL- $1 \beta$ and

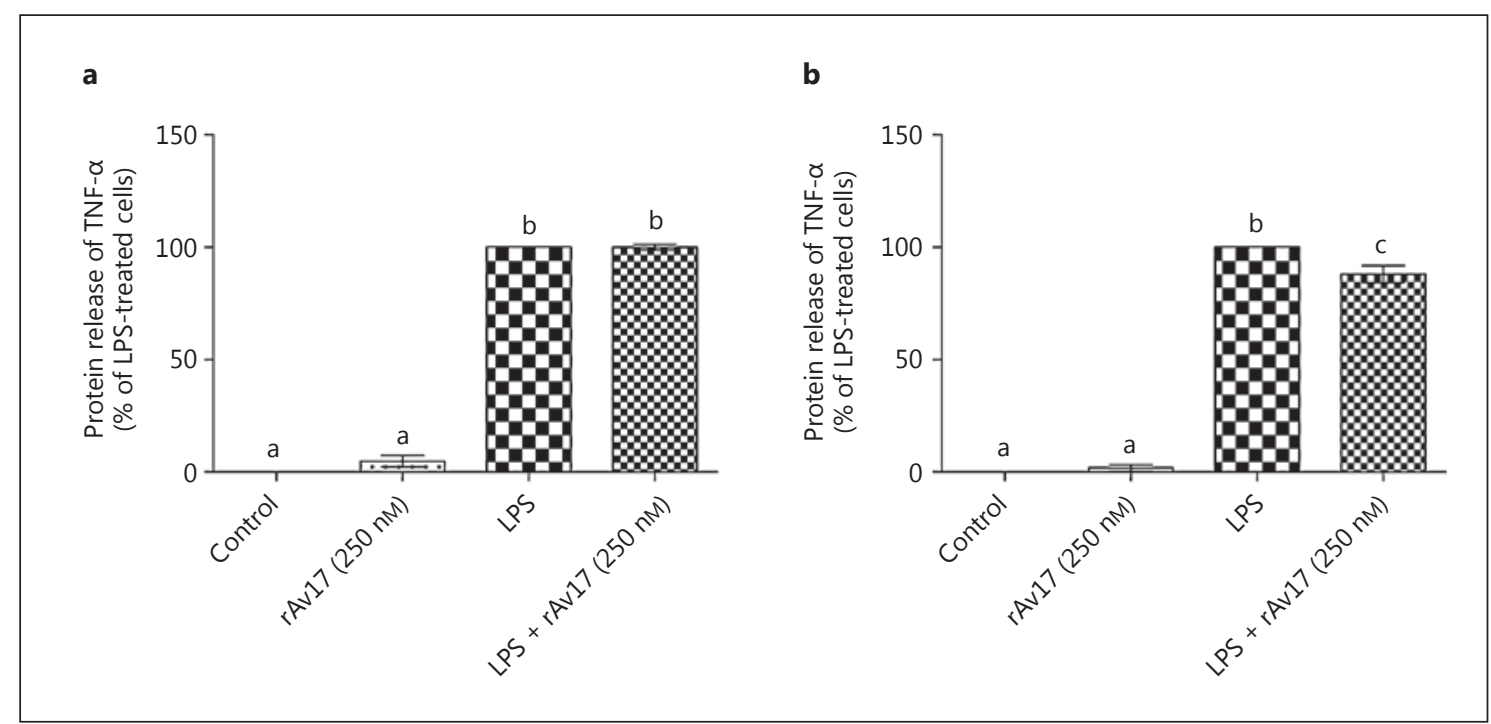

Fig. 4. a, b rAv17 inhibits proinflammatory TNF- $\alpha$ release by microglia in a time-dependent manner. Cells were stimulated for 6 (a) and $24 \mathrm{~h}$ (b) with rAv17 (250 nM), LPS (10 ng/ml) and simultaneously with rAv17 + LPS, respectively. TNF- $a$ protein release was measured by ELISA using the BD-OptEIA TNF-ELISA kit and results for cells treated with $\mathrm{rAv17}$ were compared to those stimu-

Fig. 3. a-f rAv17 inhibits proinflammatory cytokine mRNA expression by microglia in a time-dependent manner. Cells were stimulated for $6(\mathbf{a}, \mathbf{c}, \mathbf{e})$ and $24 \mathrm{~h} \mathrm{(b,} \mathrm{d,} \mathrm{f)} \mathrm{with} \mathrm{rAv} 17$ (250 nM at $6 \mathrm{~h}, 250$ and $500 \mathrm{nM}$ at $24 \mathrm{~h})$, LPS $(10 \mathrm{ng} / \mathrm{ml})$ and simultaneously with rAv17 + LPS, respectively. The expression of mRNA was analyzed using TaqMan q-PCR and results for cells treated with rAv17 were compared to those stimulated solely with LPS. 18s lated solely with LPS. All data were assessed from at least 3 independent experiments. Letters $(a, b)$ indicate clusters of experimental groups which are significantly different from each other $(\mathrm{p}<$ 0.05 ; detailed $\mathrm{p}$ values are given in the text). All data are the mean $\pm \operatorname{SEM}(95 \%$ CI values are given in the text).

RNA (a housekeeping gene) was used as the internal control. All data were assessed from at least 3 independent experiments, each run in duplicate. Letters $(a, b, c)$ indicate clusters of experimental groups which are significantly different from each other $(\mathrm{p}<0.05$; detailed $p$ values are given in the text). All data are the mean \pm SEM (95\% CI values are given in the text). 


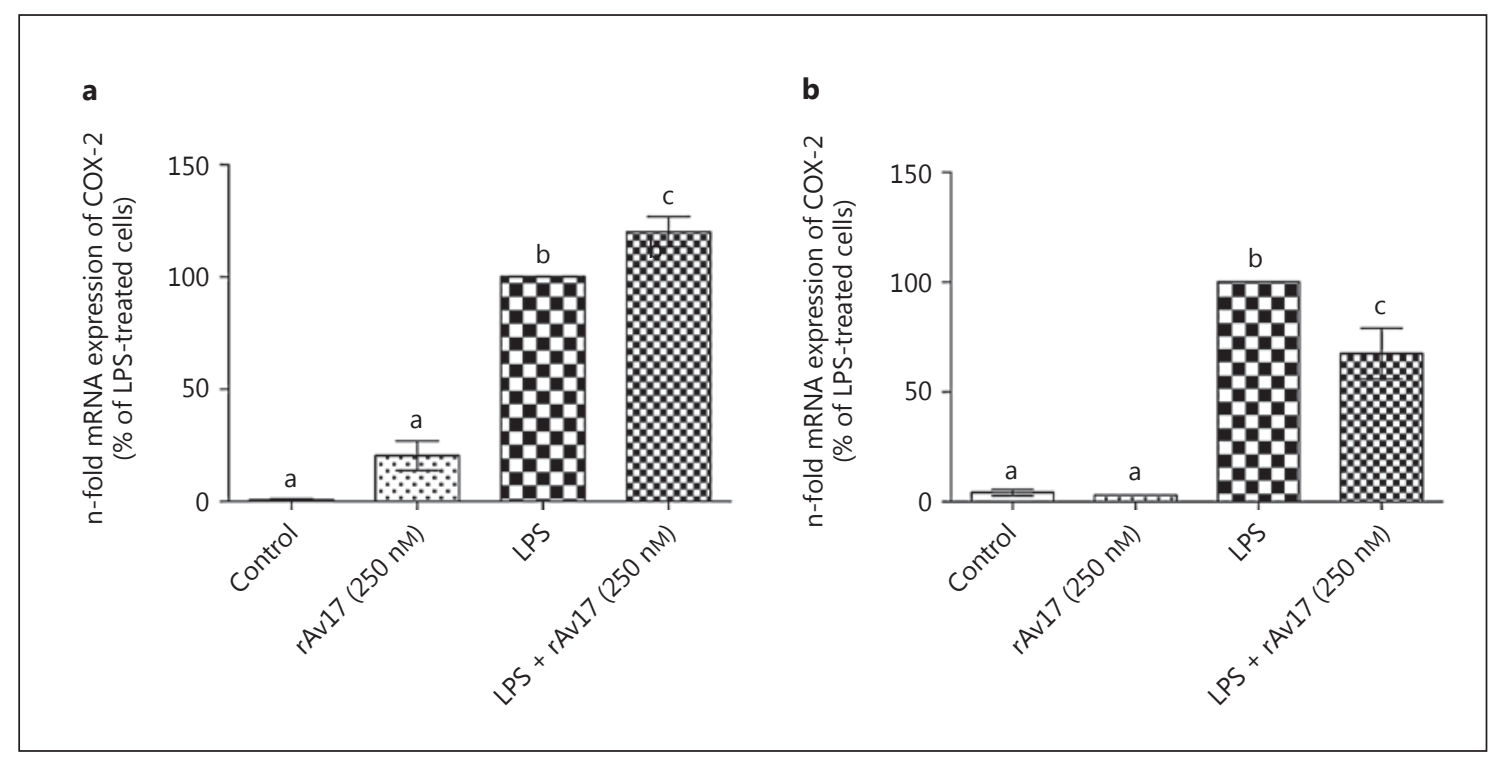

Fig. 5. a, b Time-dependent effects of rAv17 on LPS-induced COX-2 mRNA expression in cultivated microglia. Cells were stimulated for 6 (a) and $24 \mathrm{~h} \mathrm{(b)} \mathrm{with} \mathrm{rAv17} \mathrm{(250} \mathrm{nM),} \mathrm{LPS} \mathrm{(10} \mathrm{ng/ml)}$ and simultaneously with rAv17 + LPS, respectively. The expression of mRNA was analyzed using TaqMan q-PCR and results for cells treated with rAv17 were compared to those stimulated solely with LPS. 18s RNA (a housekeeping gene) was used as the internal control. The data were assessed from at least 3 independent experiments, each run in duplicate. Letters $(a, b, c)$ indicate clusters of experimental groups which are significantly different from each other $(\mathrm{p}<0.05$; detailed $\mathrm{p}$ values are given in the text). All data are the mean \pm SEM (95\% CI values are given in the text).
TNF- a mRNAs. In contrast, rAv17 (250 nM) significantly reduced the mRNA-levels of all the measured cytokines after $24 \mathrm{~h}$ (fig. 3a-f): IL-1 $\beta$ : $66.0 \pm 9.71 \%$; 95\% CI 24.21107.8; $\mathrm{p}<0.01$; IL-6: $80.33 \pm 5.49 \%$; 95\% CI 56.72-103.9; $\mathrm{p}<0.01$; TNF- $\alpha: 61.67 \pm 7.97 ; 95 \%$ CI 27.4-95.94; $\mathrm{p}<$ 0.05). Application of rAv17 in a higher molecular dose $(500 \mathrm{nM})$ reduced the mRNA expression of all investigated proinflammatory cytokines and showed distinct differences compared to low-dose rAv17 + LPS after $24 \mathrm{~h}$ [LPS vs. LPS + rAv17 (250 nM): IL-1 $\beta, 70.7 .0 \pm 7.04 \%$; 95\% CI 48.3-93.1; p < 0.01; IL-6, $60.8 \pm 15.8 \%$; 95\% CI $10.6-111.0 ; \mathrm{p}<0.05$; TNF- $\alpha, 78.4 \pm 5.29 ; 95 \%$ CI $55.7-$ $101.0 ; \mathrm{p}>0.05]$. There were no statistical significant differences when both $\mathrm{rAv} 17$ doses were compared. The reduced level of TNF- $\alpha$ mRNA is in line with decreased protein levels of TNF- $\alpha$ measured by ELISA of cell culture supernatant. Here, rAv17 (250 nM) had no effect on the LPS-induced TNF- $\alpha$ release after $6 \mathrm{~h}(100.1 \pm 1.28 \%$; $95 \%$ CI 96.01-104.2), but significantly $(\mathrm{p}<0.01)$ reduced its release after $24 \mathrm{~h}(88.02 \pm 3.80 \%$; $95 \%$ CI 75.92-100.1; fig. $4 a, b)$. Thus, no immediate effect of rAv17 could be seen after $6 \mathrm{~h}$, but it significantly reduced all measured proinflammatory cytokine mRNAs and the secreted TNF- $\alpha$ at $24 \mathrm{~h}$.

\section{rAv17 Reduces the mRNA Expression of COX-2}

in a Time-Dependent Manner

The proinflammatory enzyme COX-2 is associated with microglia activation by the production of the proinflammatory protein PGE2 (prostaglandin E2) [4]. Thus, we measured the effect of rAv17 $(250 \mathrm{nM})$ on the LPSinduced COX-2 expression via q-PCR as a marker of microglia activation (fig. 5a, b). rAv17 alone had no significant effect (6 h: $20.4 \pm 6.59 \%$; $95 \%$ CI $2.11-38.68 ; 24$ h: $3.00 \pm 0.01 ; 95 \%$ CI 3.0-2.99), whereas LPS strongly upregulated COX-2 mRNA production at 6 and $24 \mathrm{~h}$ (both $100 \%)$. The concomitant exposure of microglia to rAv17 and LPS showed an increase of COX-2 mRNA expression after 6 h (120.2 $\pm 6.78 \%$; 95\% CI 101.4-139.0; p < 0.05), whereas a significant $(\mathrm{p}<0.05)$ reduction was observed after $24 \mathrm{~h}(67.50 \pm 11.61 ; 95 \%$ CI 30.56-104.4; $\mathrm{p}<0.05)$. This pattern again supports the capacity of rAv17 to reduce proinflammatory responses after a lag phase.

\section{rAv17 Enhances IL-10 mRNA Expression in Resting and Activated Microglia}

Microglia were again stimulated with rAv17 (250 nM) alone and together with LPS. rAv17 alone induced a strong and significant $(\mathrm{p}<0.01)$ production of IL-10 mRNA at 


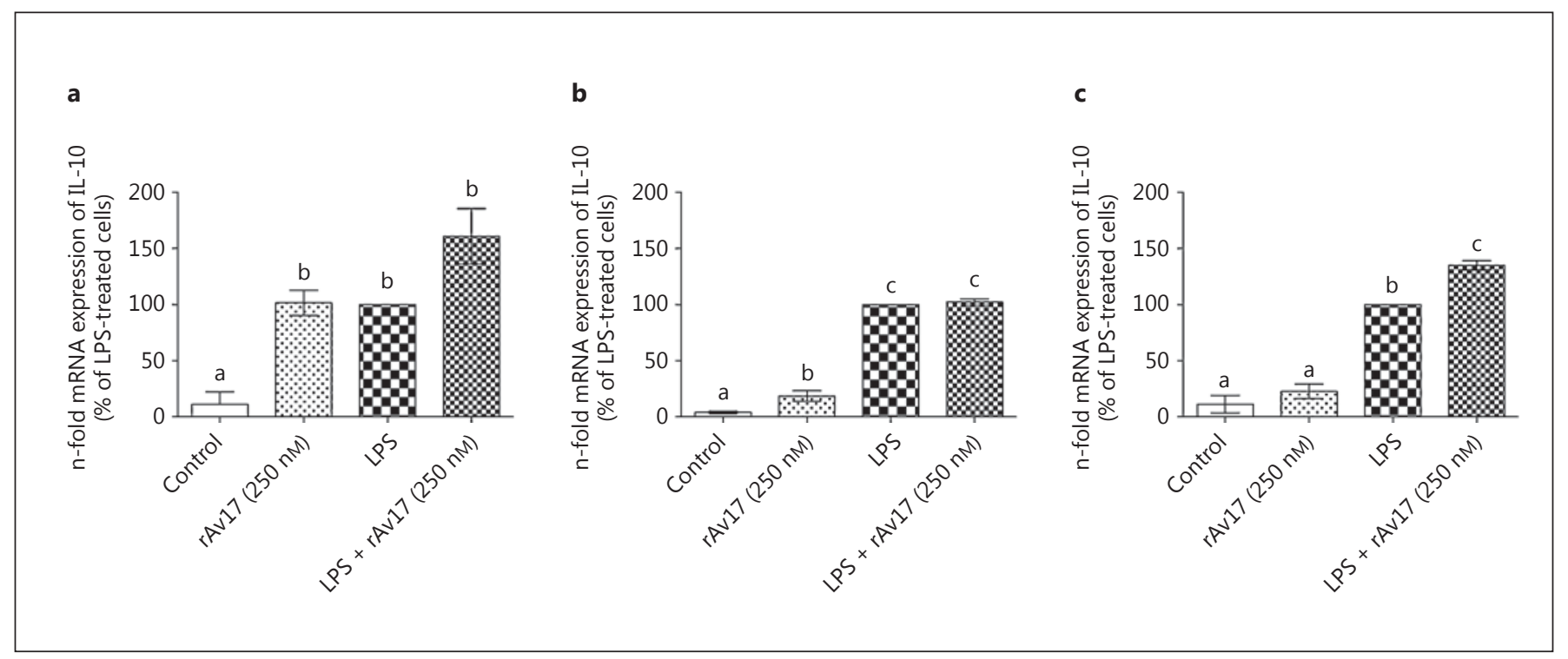

Fig. 6. a-c rAv17 enhances IL-10 mRNA expression in resting and in activated microglia. Cells were stimulated for 2 (a), 6 (b) and $24 \mathrm{~h}$ (c) with rAv17 $(250 \mathrm{nM})$, LPS $(10 \mathrm{ng} / \mathrm{ml})$ and simultaneously with rAv17 + LPS, respectively. The expression of mRNA was analyzed using TaqMan q-PCR and results for cells treated with rAv17 were compared to those stimulated solely with LPS. 18s
RNA (a housekeeping gene) was used as the internal control. The data were assessed from at least 3 independent experiments, each run in duplicate. Letters $(a, b, c)$ indicate clusters of experimental groups which are significantly different from each other $(\mathrm{p}<0.05$; detailed $p$ values are given in the text). All data are the mean \pm SEM (95\% CI values are given in the text).
$2 \mathrm{~h}(101.6 \pm 11.23 \%$; 95\% CI 53.33-149.9; $\mathrm{p}<0.05)$, which decreased over time at $6 \mathrm{~h}(18.67 \pm 4.63 \% ; 95 \% \mathrm{CI}-1.26$ to $38.59 ; \mathrm{p}<0.05)$ and $24 \mathrm{~h}(22.67 \pm 6.33 \%$; $95 \% \mathrm{CI}-4.58$ to 49.92 ; not significant; fig. $6 \mathrm{a}-\mathrm{c})$. This suggests a shortterm induction of IL-10 production by rAv17 alone. LPS, on the other hand, induces a strong production of IL-10 mRNA (100\%) over the entire measurement period (fig. 6a-c). Coexposure to rAv17 shows an increase of IL10 production at $2 \mathrm{~h}$ (trend: $160.9 \pm 24.69 \%$; $95 \%$ CI $54.68-$ 267.1; not significant) and no difference at $6 \mathrm{~h}(102.2 \pm$ 2.86\%; 95\% CI 89.9-114.5; not significant). Interestingly, a significant increase of the IL-10 mRNA level in costimulated microglia could be detected at $24 \mathrm{~h}$ (135.0 $\pm 4.04 \%$; 95\% CI 117.6-152.4; $\mathrm{p}<0.05)$. These results indicate that rAv17 induces a brief response $(2 \mathrm{~h})$ in IL-10 mRNA production in resting microglia. In LPS-stimulated cells, a short-term response could be seen after $2 \mathrm{~h}$ (trend); as for resting microglia over a longer period, an effect could be seen in IL-10 mRNA production after $24 \mathrm{~h}$.

\section{rAv17 Inhibits the Translocation of NF- $\kappa B$ in Microglia}

The transcription factor NF- $\mathrm{kB}$ promotes the expression of inflammatory genes such as iNOS, COX-2, IL-1 $\beta$,
IL- 6 and TNF- $\alpha$ after translocation from the cytosol into the nucleus [22]. To study potential signaling pathways affected by rAv17, we investigated the effect of the parasite protein on NF- $\mathrm{kB}$ activation. Therefore, translocation of NF- $\mathrm{kB}$ was visualized by immunocytochemical staining of its subunit p65 in cells exposed to rAv17 (250 $\mathrm{nM}$ ) or LPS after $60 \mathrm{~min}$. Resting microglia (fig. 7a) showed a comparable cytoplasmic staining ( $83.8 \pm 9.66 \%$; 95\% CI 59.0-109.0; $\mathrm{p}>0.05$ ) compared to LPS, but a distinctly reduced nuclear staining $(14.5 \pm 1.2 \%$; $95 \%$ CI 11.4-17.6; $\mathrm{p}<0.001)$. This pattern was not appreciably altered by rAv17 alone (fig. $7 \mathrm{c} ; \mathrm{rAv} 17$ vs. control: nucleus, $10.1 \pm 1.18 \%$; 95\% CI 7.5-12.7; p > 0.05; cytosol, $82.1 \pm$ 7.61\%; 95\% CI 64.9-99.3; p > 0.05). In contrast, exposure to LPS led to a strong increase in nuclear staining (fig. 7b). On the contrary, cells simultaneously treated with LPS and rAv17 displayed an increase of cytoplasmic staining (166.0 $\pm 15.5 \%$; 95\% CI 132.0-200.1; p < 0.014) compared to LPS, but a reduced nuclear localization of the transcription factor (LPS + rAv17 vs. LPS: $28.4 \pm 1.81 \%$; 95\% CI 24.3-32.5; $\mathrm{p}<0.001)$. Thus, rAv17 clearly interfered with the translocation of NF- $\mathrm{kB}$ (fig. 7d). These data show that $\mathrm{rAv} 17$ inhibits NF-kB translocation to the nucleus in microglia. 
Fig. 7. a-d rAv17 inhibits nuclear translocation of transcription factor NF- $\kappa \mathrm{B}$ in microglia. Representative photomicrographs of in vitro-cultivated microglia. a Resting microglia cells (control). b LPS (10 ng/ml)stimulated microglia (positive control). c The addition of rAv17 (250 nM) did not appreciably alter the NF-kB-appearance of resting microglia. d rAv17 (250 nM) inhibited the LPS (10 ng/ml)-induced NF- $\mathrm{kB}$ translocation. Results for quantitative analysis are given in the text. Cells were cultivated upon cover glasses for $24 \mathrm{~h}$ and stimulated with the indicated reagents for 60 min. After fixation with Zamboni's reagent, cells were stained with the primary antibody (NF-kB p65; Santa Cruz Biotechnology) and the NF- $\mathrm{kB}$ distribution was visualized with fluorescing anti-rabbit antibodies (Alexa Fluor, Invitrogen) in fluorescence microscopy. Scale bar $=20 \mu \mathrm{m}$.
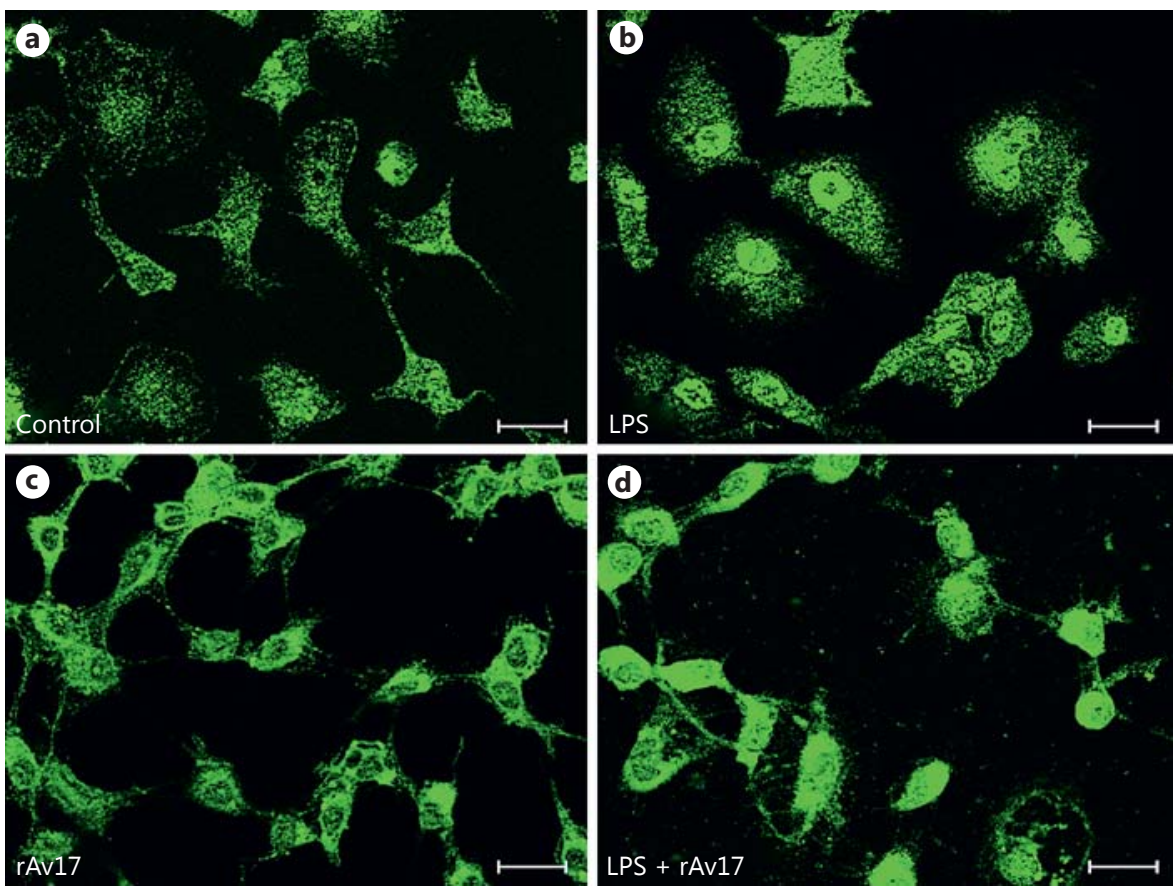

rAv17 Inhibits the ERK Pathway in Microglia

The MAPK signaling pathway ERK1/2 was examined by Western blot analysis of the transient ERK-phosphorylation (pERK1/2). MAPK signaling pathways are also involved in the regulation of inflammatory responses [23]. Stimulation with rAv17 (250 nM) for $15 \mathrm{~min}$ did not significantly differ the basic ERK phosphorylation (control: $53.2 \pm 5.33 \%$; $95 \%$ CI 30.3-76.2; vs. rAv17: $47.2 \pm 5.28 \%$; 95\% CI 24.4-69.9; $\mathrm{p}>0.05$ ), whereas the addition of LPS strongly upregulated the amount of phosphorylated pERK1/2 (100\%) in microglia. The simultaneous treatment with rAv17 reduced activation of the ERK1/2 pathway (fig. 8a, b) as could be concluded by the significantly $(\mathrm{p}<0.01)$ decreased amount of pERK1/2 (82.5 $\pm 4.16 \%$; 95\% CI 69.2-95.7; $\mathrm{p}<0.05)$. Therefore, rAv17 also seems to interfere with the ERK signaling pathway.

\section{Discussion}

This study showed that the parasite-derived immunomodulator rAv17 alters the LPS-induced proinflammatory phenotype of rat microglia in vitro. Stimulation with LPS led to morphological changes, cytokine dysregulation (IL-1 $\beta$, IL-6, TNF- $\alpha$, IL-10) and the upregulation of certain enzymes (iNOS, COX-2), as well as a nuclear translocation of NF- $\mathrm{kB}$ and phosphorylation of ERK in microg- lia. After LPS stimulation, microglia displayed an amoeboid-like phenotype with large soma and a reduced number of pseudopodia. On the other hand, the untreated control group seemed to be more ramified. Costimulation of microglia with LPS and rAv17 led to a rather ramified morphology, giving the first evidence for a change in activation state [24]. To evaluate whether this change in phenotype leads to a transcriptional upregulation of inflammation-associated genes, qPCR measurements were carried out at different time points poststimulation $(2,6$ and $24 \mathrm{~h}$ ). As proinflammatory markers, iNOS and the subsequent production of $\mathrm{NO}$ were analyzed. Additionally, the proinflammatory cytokines IL- $1 \beta$, IL- 6 , TNF- $\alpha$ and the PGE2-producing COX-2 were evaluated at the mRNA level. Moreover, TNF- $\alpha$ secretion was measured on the protein level using a specific ELISA. As an antiinflammatory cytokine, the IL-10 mRNA level was exerted. Upon stimulation with LPS all inflammatory agents, including IL-10, were significantly upregulated at 6 and $24 \mathrm{~h}$. The upregulation of proinflammatory agents was significantly reduced at $24 \mathrm{~h}$ in LPS/rAv17 costimulated cells, but not at $6 \mathrm{~h}$. The addition of rAv17 in a higher molecular dosage displayed comparable results as those seen for low-dose rAv17. This indicates that the lower concentration $(250 \mathrm{nM})$ of rAv17 was already exerting the maximum effect. In contrast, rAv17 alone did not induce the transcription of any of these proinflammatory agents in 
Fig. 8. a, b rAv17 inhibits the ERK-pathway in microglia. Cells were stimulated for 15 min with rAv17 (250 nM), LPS (10 ng/ $\mathrm{ml}$ ) and simultaneously with rAv17 + LPS, respectively. Activated ERK (pERK1/2) species were detected by Western blot analysis with antibodies specific for the pERK1/2. The amount of protein loaded in each line was confirmed by measuring the amount of ERK1/2 using antibodies against the nonphosphorylated form of ERK (ERK2). a Representative Western blot diagram. b Blots were subjected to densitometry and results for cells treated with rAv17 were compared to those stimulated solely with LPS (100\%). The data were assessed from three independent experiments. Letters $(a, b, c)$ indicate clusters of experimental groups which are significantly different from each other $(\mathrm{p}<0.05$; detailed $\mathrm{p}$ values are given in the text). All data are the mean \pm SEM $(95 \%$ CI values are given in the text).
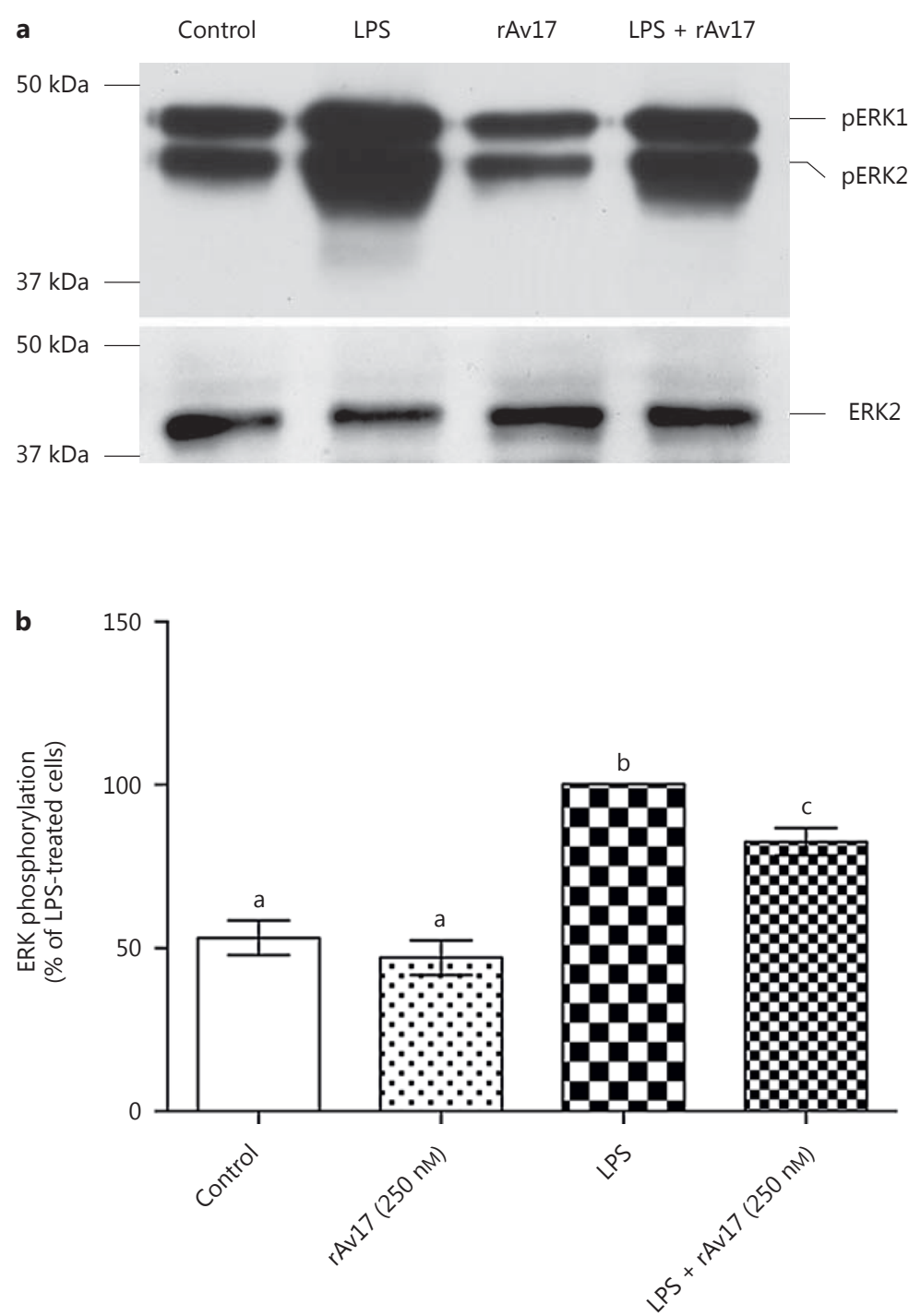

microglia at any time point. A different picture exists for IL-10. Here, a short time increase can be seen at $2 \mathrm{~h}$ for cells stimulated with rAv17 at a low dose. This upregulation decreases over time until becoming insignificant at $24 \mathrm{~h}$. In LPS/rAv17 costimulated samples, an increase can be seen after $2 \mathrm{~h}$ (trend), which might be due to the short time effect seen for $\mathrm{rAv} 17$ stimulation alone. After $6 \mathrm{~h}$ no difference can be seen between LPS/rAv17 and LPS stimulation. Interestingly, the IL-10 level was significantly higher at $24 \mathrm{~h}$ in costimulated LPS/rAv17 compared to LPS-stimulated cells. Thus, we might see two overlaying effects here. One short-term effect $(2 \mathrm{~h})$ where the appli- cation of rAv17 leads to an LPS-independent increase in IL-10 mRNA, and one long-term effect $(24 \mathrm{~h})$ where it leads to an increase of IL-10 mRNA in LPS costimulated microglia. This long-term effect is accompanied by the reduction of proinflammatory agents. Thus, rAv17 induces a clearly anti-inflammatory effect in this cell culture model of inflammation. Interestingly, another immunomodulator of A. viteae, ES-62, shows similar delayed effects on proinflammatory mediators and interferes with the NF- $\mathrm{kB}$ and MAPK signaling pathway [25].

To date, little is known about the cellular mechanism that is mediated by rAv17. It has been shown, for exam- 
ple, that microglia express the IL-10 receptors [26] and that IL-10 inhibits NF-kB-related pathways [27]. Thus, the increase in IL-10 with the parallel reduction of IL-1 $\beta$, IL-6, TNF- $\alpha$, iNOS, NO and COX-2 might display a switch in the microglial phenotype from proinflammatory to anti-inflammatory, as already described for macrophages [14]. The phenotypic plasticity observed in our study would be in line with the observations of Colton [2], who described three different activation states of microglia in the brain and proposed that downregulation of the classical activation is mainly driven by feedback regulation, with IL-10 being a key regulator. In our model there is a clear centralization of the NF- $\kappa B$ (p65) signal in LPSstimulated microglial cells. This centralization is not detectable when cells are costimulated with rAv17. Moreover, a small yet significant reduction of pERK was seen in rAv17-treated microglial cells. This points towards an additional reduction in the MAP kinase-related signaling pathways. Taken together, we see a short time upregulation of the IL-10 mRNA which is accompanied by an impaired NF- $\kappa B$ centralization and an inhibition of the MAP kinase signaling pathway. In the long term, we see a reduction of proinflammatory agents in LPS/rAv17 costimulated cells compared to LPS stimulation only, which is accompanied by an increase in the IL-10 mRNA level. One potential explanation for these results might be a negative feedback mechanism by IL-10, which is regulated by MAPK-like ERK1/2 and appears to be critical in the proinflammatory cytokine response to LPS [28]. However, evidence for such wise regulation mainly comes from monocytes [14, 29]. In addition, in the CNS, NF- $\kappa B$ activation can be negatively regulated by IL-10 [30]. Furthermore, the inhibition of the ERK1/2 pathway is a crucial mechanism in terms of alleviating neuroinflammation [23]. Therefore, we propose an indirect mechanism via negative feedback inhibition that is mediated by IL-10 as a possible explanation for the observed rAv17-mediated results in our study.

The change in cytokine expression in our study might represent a switch from a proinflammatory to an antiinflammatory phenotype. As microglial cells are major sources of proinflammatory stimuli in neurodegenerative disease [31] (e.g. Parkinson's disease), a switch from a pro- to an anti-inflammatory phenotype is of high interest. The eventual neuroprotective effects of these rAv17treated microglia need to be evaluated in future studies.

Other studies corroborate the potential of a neuroimmunomodulatory therapy in ND by parasite-derived products. The intraperitoneal administration of soluble helminth products induced a significant suppression of symptoms in experimental autoimmune encephalomyelitis, representing a valid murine model for multiple sclerosis [32]. In addition, clinical trials with eggs from the nonpathogenic helminth Trichuris suis have led to reduced numbers of gadolinium-enhancing MRI lesions in patients suffering from multiple sclerosis. Interestingly, this was accompanied by a downregulation of Th1-associated cytokines and increased serum levels of IL-10 [33, 34]. Components such as rAv17 are optimized during a longstanding host-parasite coevolution and might offer an efficient variant of anti-inflammatory therapy in ND.

\section{Conclusion}

We demonstrated that rAv17 consequently reduced LPS-induced proinflammatory agents in a cell culture model of primary microglia. We assume that the major effect of $\mathrm{rAv} 17$ is exerted via the anti-inflammatory cytokine IL-10 and, therefore, postulate that rAv17 triggers a switch, which results in an anti-inflammatory phenotype of microglia. We hope to confirm the proposed immunomodulatory mechanisms in a more physiological model (e.g. stimulation of microglia with neuromelanin) and to deepen insights into a potentially neuroprotective property of rAv17.

\section{Acknowledgments}

We thank R. Sprang, R. Worm, M. Grell and G. Schaefer for their excellent technical assistance. We thank C. Franke for his technical support.

\section{Disclosure Statement}

The authors declare that they have no competing interests.

\begin{tabular}{|c|c|}
\hline References & $\begin{array}{l}\text { 1 Cherry JD, Olschowka JA, O'Banion MK: } \\
\text { Neuroinflammation and M2 microglia: the } \\
\text { good, the bad, and the inflamed. J Neuroin- } \\
\text { flammation 2014;11:98. } \\
\text { Colton CA: Heterogeneity of microglial acti- } \\
\text { vation in the innate immune response in the } \\
\text { brain. J Neuroimmune Pharmacol 2009; } 4 \text { : } \\
\text { 399-418. } \\
3 \text { Glass CK, Saijo K, Winner B, Marchetto MC, } \\
\text { Gage FH: Mechanisms underlying inflamma- } \\
\text { tion in neurodegeneration. Cell 2010;140: } \\
\text { 918-934. }\end{array}$ \\
\hline
\end{tabular}

Behrendt/Arnold/Brueck/Rickert/Lucius/ Hartmann/Klotz/Lucius 
-4 Teismann P, Tieu K, Choi DK, Wu DC, Naini A, Hunot S, Vila M, Jackson-Lewis V, Przedborski S: Cyclooxygenase-2 is instrumental in Parkinson's disease neurodegeneration. Proc Natl Acad Sci USA 2003;100:5473-5478.

$\checkmark 5$ Hunot S, Boissiere F, Faucheux B, Brugg B, Mouatt-Prigent A, Agid Y, Hirsch EC: Nitric oxide synthase and neuronal vulnerability in Parkinson's disease. Neuroscience 1996;72: 355-363.

6 Knott C, Stern G, Wilkin GP: Inflammatory regulators in Parkinson's disease: iNOS, lipocortin-1, and cyclooxygenases- 1 and -2. Mol Cell Neurosci 2000;16:724-739.

-7 De Lella Ezcurra AL, Chertoff M, Ferrari C, Graciarena M, Pitossi F: Chronic expression of low levels of tumor necrosis factor- $\alpha$ in the substantia nigra elicits progressive neurodegeneration, delayed motor symptoms and microglia/macrophage activation. Neurobiol Dis 2009;37:630-640.

8 Gayle DA, Ling Z, Tong C, Landers T, Lipton JW, Carvey PM: Lipopolysaccharide (LPS)induced dopamine cell loss in culture: roles of tumor necrosis factor- $\alpha$, interleukin- $1 \beta$, and nitric oxide. Brain Res Dev Brain Res 2002 133:27-35.

9 Ferrari CC, Pott Godoy MC, Tarelli R, Chertoff M, Depino AM, Pitossi FJ: Progressive neurodegeneration and motor disabilities induced by chronic expression of IL- $1 \beta$ in the substantia nigra. Neurobiol Dis 2006;24:183193.

10 Maizels RM, Pearce EJ, Artis D, Yazdanbakhsh M, Wynn TA: Regulation of pathogenesis and immunity in helminth infections. J Exp Med 2009;206:2059-2066.

-11 Manoury B, Gregory WF, Maizels RM, Watts C: $B m$-CPI-2, a cystatin homolog secreted by the filarial parasite Brugia malayi, inhibits class II MHC-restricted antigen processing. Curr Biol 2001;11:447-451.

-12 Schnoeller C, Rausch S, Pillai S, Avagyan A, Wittig BM, Loddenkemper C, Hamann A, Hamelmann E, Lucius R, Hartmann S: A helminth immunomodulator reduces allergic and inflammatory responses by induction of IL-10-producing macrophages. J Immunol 2008; 180:4265-4272.
13 Hartmann S, Kyewski B, Sonnenburg B, Lucius R: A filarial cysteine protease inhibitor down-regulates $\mathrm{T}$ cell proliferation and enhances interleukin-10 production. Eur J Immunol 1997;27:2253-2260.

14 Klotz C, Ziegler T, Figueiredo AS, Rausch S, Hepworth MR, Obsivac N, Sers C, Lang R, Hammerstein P, Lucius R, Hartmann S: A helminth immunomodulator exploits host signaling events to regulate cytokine production in macrophages. PLoS Pathog 2010; 7:e1001248

15 Lucius R, Sievers J, Mentlein R: Enkephalin metabolism by microglial aminopeptidase $\mathrm{N}$ (CD13). J Neurochem 1995;64:1841-1847.

16 Dutta G, Zhang P, Liu B: The lipopolysaccharide Parkinson's disease animal model: mechanistic studies and drug discovery. Fundam Clin Pharmacol 2008;22:453-464.

17 Cunningham C: Microglia and neurodegeneration: the role of systemic inflammation. Glia 2013;61:71-90.

18 Kettenmann H, Hanisch UK, Noda M, Verkhratsky A: Physiology of microglia. Physiol Rev 2011;91:461-553.

19 Yuste JE, Tarragon E, Campuzano CM, RosBernal F: Implications of glial nitric oxide in neurodegenerative diseases. Front Cell Neurosci 2015;9:322.

20 Kitamura Y, Matsuoka Y, Nomura Y, Taniguchi T: Induction of inducible nitric oxide synthase and heme oxygenase- 1 in rat glial cells. Life Sci 1998;62:1717-1721.

21 Wang X, Chen S, Ma G, Ye M, Lu G: Involvement of proinflammatory factors, apoptosis, caspase- 3 activation and $\mathrm{Ca}^{2+}$ disturbance in microglia activation-mediated dopaminergic cell degeneration. Mech Ageing Dev 2005; 126:1241-1254.

22 Pahl HL: Activators and target genes of Rel/ NF- $\kappa$ B transcription factors. Oncogene 1999; 18:6853-6866.

23 Kim EK, Choi EJ: Compromised MAPK signaling in human diseases: an update. Arch Toxicol 2015;89:867-882.

24 abd-el-Basset E, Fedoroff S: Effect of bacterial wall lipopolysaccharide (LPS) on morphology, motility, and cytoskeletal organization of microglia in cultures. J Neurosci Res 1995;41: 222-237.

25 Al-Riyami L, Harnett W: Immunomodulatory properties of ES-62, a phosphorylcholinecontaining glycoprotein secreted by Acanthocheilonema viteae. Endocr Metab Immune Disord Drug Targets 2012;12:45-52.
26 Ledeboer A, Breve JJ, Wierinckx A, van der Jagt S, Bristow AF, Leysen JE, Tilders FJ, van Dam AM: Expression and regulation of interleukin-10 and interleukin-10 receptor in rat astroglial and microglial cells. Eur J Neurosci 2002;16:1175-1185.

27 Heyen JR, Ye S, Finck BN, Johnson RW: Interleukin (IL)-10 inhibits IL-6 production in microglia by preventing activation of NF- $\mathrm{KB}$. Brain Res Mol Brain Res 2000;77:138-147.

28 Bachstetter AD, Xing B, Van Eldik LJ: The p38 a mitogen-activated protein kinase limits the CNS proinflammatory cytokine response to systemic lipopolysaccharide, potentially through an IL-10 dependent mechanism. J Neuroinflammation 2014;11:175.

29 Bouhamdan M, Bauerfeld C, Talreja J, Beuret L, Charron J, Samavati L: MEK1 dependent and independent ERK activation regulates IL10 and IL- 12 production in bone marrow derived macrophages. Cell Signal 2015;27: 2068-2076.

30 Kaltschmidt B, Widera D, Kaltschmidt C: Signaling via NF- $\mathrm{KB}$ in the nervous system. Biochimica Biophys Acta 2005;1745:287-299.

31 Tansey MG, Goldberg MS: Neuroinflammation in Parkinson's disease: its role in neuronal death and implications for therapeutic intervention. Neurobiol Dis 2010;37:510-518.

32 Kuijk LM, Klaver EJ, Kooij G, van der Pol SM, Heijnen P, Bruijns SC, Kringel H, Pinelli E, Kraal G, de Vries HE, Dijkstra CD, Bouma G, van Die I: Soluble helminth products suppress clinical signs in murine experimental autoimmune encephalomyelitis and differentially modulate human dendritic cell activation. Mol Immunol 2012;51:210-218.

- 33 Benzel F, Erdur H, Kohler S, Frentsch M, Thiel A, Harms L, Wandinger KP, Rosche B: Immune monitoring of Trichuris suis egg therapy in multiple sclerosis patients. J Helminthol 2012;86:339-347.

34 Fleming JO, Isaak A, Lee JE, Luzzio CC, Carrithers MD, Cook TD, Field AS, Boland J, Fabry Z: Probiotic helminth administration in relapsing-remitting multiple sclerosis: a phase 1 study. Mult Scler 2011;17:743-754. 